\title{
Irrational Use of Antibiotics, in Different Age Groups of Karachi: A Wake- up Call for Antibiotic Resistance and Future Infections
}

\author{
Hameed $\mathbf{A}^{1 *}$, Naveed $\mathbf{S}^{1}$, Qamar $\mathrm{F}^{1}$, Alam $\mathrm{T}^{\mathbf{1}, 3}$, Abbas $\mathbf{S S}^{1,2}$ and Sharif $\mathbf{N}^{\mathbf{1}}$ \\ ${ }^{1}$ Faculty of Pharmacy, Jinnah University for Women, Nazimabad, Karachi, Pakistan \\ ${ }^{2}$ Faculty of Pharmacy, University of Karachi, Pakistan \\ ${ }^{3}$ Central Drug Laboratory, Drug Regulatory Authority of Pakistan, SMCHS, Karachi, Pakistan
}

\begin{abstract}
Antibiotics also acknowledged as antibacterial medications that inhibits or slows down the growth of bacteria From discovery of antibiotics, decade added to the life expectancy of man. Irrational use of antibiotics can lead to resistance towards wide range of pathogens and bacteria. The emergence of resistance is threatening the usefulness of antibiotics. There is a dearth of novel agents to encounter the challenge of resistant strains. Our study aims to find out the current practice of irrational antibiotics prescribed by physicians to children and use of antibiotics among adults without prescription or with refilling of prescriptions having antibiotics as a self-medication. A cross-sectional method was use to collect data from different hospitals (from 100 children) and public places (from 200 adults) of Karachi, Pakistan. According to our survey, antibiotics are prescribed to $76 \%$ children, although many children have no need of it. According to our survey report on 200 adults $19.5 \%$ use antibiotics often, $23 \%$ purchase antibiotic without prescriptions, $52.5 \%$ never seek advice from health care professionals, $17 \%$ adults not follow complete course of antibiotics, $26.5 \%$ experienced serious side effects from antibiotics, $41 \%$ don't know that the misuse of antibiotic is harmful, while $27.5 \%$ thinks that the antibiotics they used will be effective in future for the same infection $39 \%$ adults refills the previous prescription with antibiotics for the same infections they experienced in past whereas $25.5 \%$ adults share their prescription of antibiotic with others. We concluded that the major factor that leads to irrational use of antibiotic and its resistance is lack of awareness and improper prescription data by physicians.
\end{abstract}

Keywords: Antibiotics; Bacteria; Irrational use; Resistance; Prescription

\section{Introduction}

The discovery of antibiotics existed one of the supreme significant events in medical history and is said to have added a decade to the life expectancy of man [1]. Antibiotics also known as antibacterial medications that inhibits or slows down the growth of bacteria. Bacteria are microscopic organisms and the word bacteria are the plural of bacterium [2]. We have special white blood cells that attack harmful bacteria. Even if symptoms do occur, our immune system can usually muddle through and drive away the infection. There are circumstances, on the other hand, when it is all too much and some help is needed from antibiotics. Antibiotic therapy is mounting more multifaceted, thus making appropriate antibiotic prescribing increasingly challenging. Antibiotics-related problems (ARPs) are a most important well-being dispute for hospitalized patients. Children and Infants represent a large part of the population in the developing countries [3]. Pediatric population is prone to suffer from recurrent contagions of gastrointestinal system (GIT) and respiratory tract. Lower respiratory tract infections are the leading cause of death in children below the age of 5 years [4]. Acute respiratory tract infection (RTI), acute diarrhoea and viral fever are the supreme conjoint illnesses book-keeping for the major proportion of pediatric visits [5]. Several studies come together on antibiotic prescribing insolences in hospitalized children indicate that children admitted to hospitals receive antibiotics and widespread misuse has been reported [6]. Most upper respiratory tract infections, such as the common cold and sore throats are usually caused by viruses. Antibiotics do not work against these viruses [2].

Although the antibiotics obligate extensive variety of uses but still there mistreatment can lead to resistance towards wide range of pathogens and bacteria [7]. Antibiotic resistance is a major challenge world-wide [8]. If antibiotics are overused or used incorrectly there is a chance that the bacteria will turn into resistant-the antibiotic becomes less effective against that type of bacterium. Therefore it is very important to use of antibiotics rationally [2]. It is seen in Grampositive as well Gram-negative organisms; in healthcare-associated over and above community-acquired infections. The Infectious Diseases Society of America had identified six organisms as being the supreme challenging; the so-called ESKAPE organisms (namely Enterococcus faecium, Staphylococcus aureus, Klebsiella pneumoniae, Acinetobacter baumannii, Pseudomonas aeruginosa and Enterobacter sp.) [8]. Resistance is not a new spectacle. Sir Alexander Fleming in his Nobel Lecture warned that, "It is not difficult to make microbes resistant to penicillin in the research laboratory by exposing them to concentrations not sufficient to kill them, and the same mechanism has sporadically occurred in the body" [9]. There is a significant decrease in the involvement of top pharmaceutical companies in the expanse of anti-microbial drug development. The reasons are understandable. The cost of bringing an invention from bench to bed-side is exorbitantly high. Antibiotics are usually used for short durations, and new potent antibiotics are often kept in reserve to be used solitary in patients who have not responded to more conventional agents. The emergence of resistance is threatening the effectiveness of antibiotics.

*Corresponding author: Hameed A, Faculty of Pharmacy, Jinnah University for Women, Nazimabad, Karachi, Pakistan, Tel: 922136620859; E-mail: asra_hameed1@hotmail.com

Received August 15, 2016; Accepted August 25, 2016; Published September 05, 2016

Citation: Hameed A, Naveed S, Qamar F, Alam T, Abbas SS, et al. (2016) Irrational Use of Antibiotics, in Different Age Groups of Karachi: A Wakeup Call for Antibiotic Resistance and Future Infections. J Bioequiv Availab 8: 242-245. doi: 10.4172/jbb. 1000302

Copyright: (c) 2016 Hameed A, et al. This is an open-access article distributed under the terms of the Creative Commons Attribution License, which permits unrestricted use, distribution, and reproduction in any medium, provided the original author and source are credited. 
There is a dearth of new agents to meet the challenge of resistant strains. Antibiotic stewardship is therefore crucial to contain resistance and to prolong the useful lives of accessible agents. A concerted struggle employing a multifaceted strategy is essential at international, national and institutional levels, and we need to work together to meet this challenge [8]. Incomplete prescription writing practice in our community is also a major case of use of antibiotics. Many parts of prescriptions are incomplete in almost all the prescriptions, whereas certain parts are inadequate or lacking in the prescriptions which may lead to over dose and toxic effects of the drugs by their miss use or abuse of drugs in individuals excluding patient or repeated use in the same patient [10].

\section{Methodology}

For the collection of data about antibiotics prescribing practice in children, we survey different pediatric wards of public and private sector hospitals and health cares in Karachi, Pakistan. The Patients were belonging to different age groups from 0 to 15 years. Data of 100 children patients about their condition and prescription was collected for analysis of irrational use of broad spectrum antibiotics in children $(n=100)$. To check the irrational use of antibiotics among adults a questionnaire was designed consisting of different close ended questions for the collection of data. Data was collected from $200(n=200)$ adults belonging to different areas of Karachi, Pakistan. A combination of open and close ended questions was used to collect data from 300 samples i.e., 100 pediatric patients and 200 adults. We have statistically analysed our result and plotted graphs (Figures 1-6).

\section{Result}

According to our survey, antibiotics are prescribed to $76 \%$ children, although many children have no need of it. According to our survey report on 200 adults $19.5 \%$ use antibiotics often, $23 \%$ purchase antibiotic without prescriptions, $52.5 \%$ never seek advice from health care professionals, $17 \%$ adults not follow complete course of antibiotics, 26.5\% experienced serious side effects from antibiotics, $41 \%$ don't know that the misuse of antibiotic is harmful, while $27.5 \%$ thinks that the antibiotics they used will be effective in future for the same infection. $39 \%$ adults refills the previous prescription with antibiotics for the same infections they experienced in past whereas $25.5 \%$ adults share their prescription of antibiotic with others (Figures 7-11)

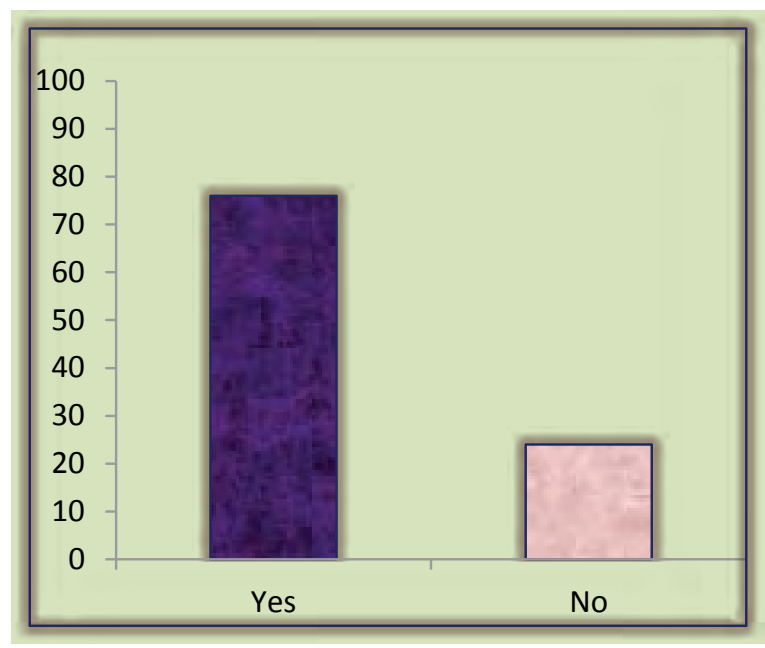

Figure 1: Use of antibiotics among children.

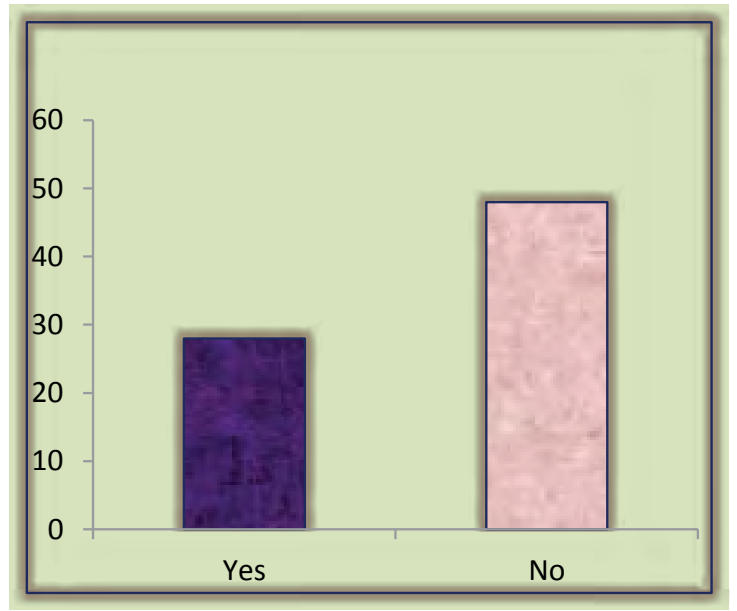

Figure 2: Irrational use of antibiotics among children.

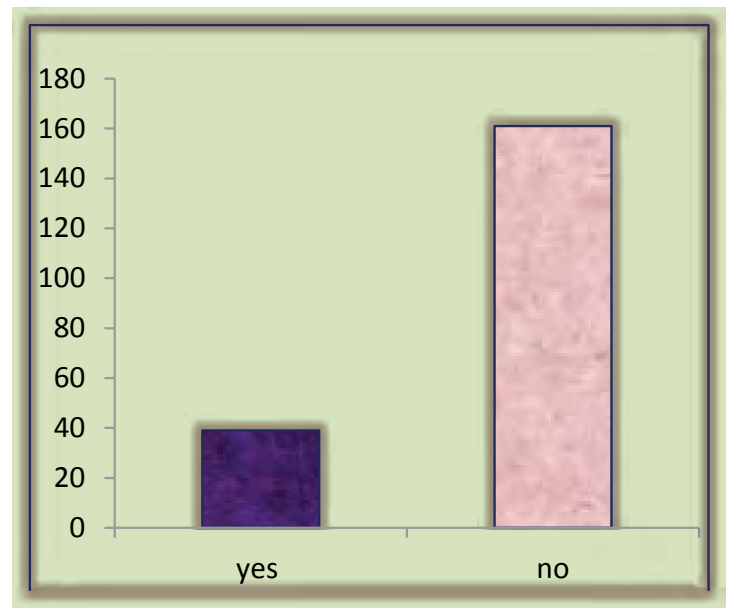

Figure 3: Often use of antibiotics

\section{Discussion}

Antibiotics are the agents that are useful for bacterial infections. Irrational use of antibiotics is a serious issue because it can lead to serious harm in future even for the simple infections as bacterial strains are becoming resistant to present antibiotics due to irrational use. Use of broad spectrum antibiotics for minor infections is also a cause of resistant of bacterial strains. Prescribing antibiotics for viral infections can also be a cause of bacterial resistance. According to our survey report about antibiotic prescribing in child patients, 76 children out of 100 patients have prescribed antibiotics while 24 children patient have no antibiotics in their prescriptions. In these 76 children patient 48 children patients have prescribed antibiotics rationally, while 28 children have irrational antibiotics prescribed. These 28 children patient have no need of antibiotics because they are suffering from viral infections and some have minor infections required simple antibiotics but they have prescribed broad-spectrum antibiotics.

Misuse of antibiotics in adult as self-medication is very common is our society. On one hand, Medical stores are selling antibiotics without prescription while on the other hand physician prescribed antibiotics but the prescription is not complete. Patients does not follow complete course of antibiotics which is the root cause of bacterial resistance. 


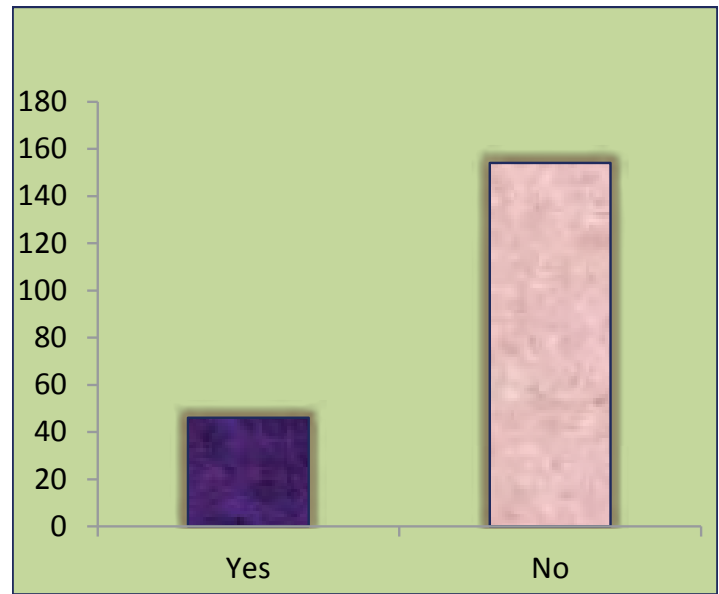

Figure 4: Purchase of antibiotics without prescription.

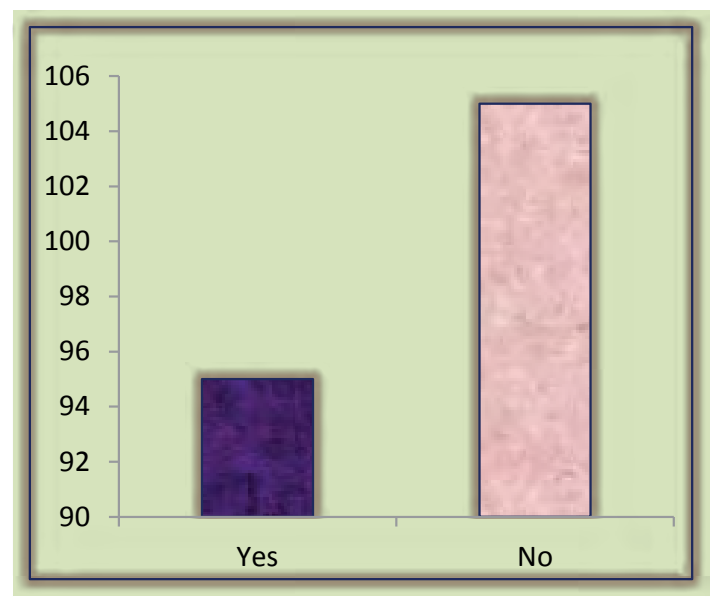

Figure 5: Seek advice from health care professionals.

According to our survey on irrational use of antibiotics in adults, we find that 39 adults use antibiotics often while 161 adults out of 200 use antibiotics rarely. A number of adults (i.e., 46) purchase antibiotics without prescription while 154 adults from a total of 200 use antibiotics after prescription from registered medical practitioners only. We find that 95 adults seek an advice from healthcare professionals when they get illness or infection while other 105 adults out of 200 never seek for advice from physicians when they suffer from infections. We find 166 adults follow complete course of antibiotics prescribed by medical practitioners while other 34 adults never follow the antibiotics course and leave them as the symptoms subsides. We concluded that 53 adults have experienced some minor or serious side effects from the use of antibiotics while other 147 adults out of 200 in our society have never experienced adverse effect from the use of antibiotics. In the survey, 118 adults in our society have awareness that misuse of antibiotics can lead to serious harm while 82 adults have no knowledge about the harms from the misuse of antibiotics. We find that 99 adults thinks that the antibiotics they are using will remain useful in future for the same infection while 55 adults thinks that this antibiotic will be no more useful for the same infection in future. On the other hand 46 adults have no idea about the usefulness of antibiotics for same condition in future. Lack of data of patient on prescription by physician is another cause of antibiotics misuse. Refilling of same prescription for same infection in future due to lacking of date of prescribing on prescription and sharing the prescription with others have same infections due to lack of patients details, to whom it is prescribed, is also very common in our society. We find that 78 adults out of 200 repeat to refills the same prescription for the same infection they experienced in the near past, while 122 adults doesn't repeats the prescription prescribed for same infection in the past. We analysed that 51 adults out of 200 share their prescription with other having same symptoms when they found their therapy beneficial to them, whereas 149 adults not share their prescriptions with other even after getting benefits from the therapy.

\section{Conclusion}

Irrational use of antibiotics is very common in our community. Physicians are prescribing irrational broad spectrum antibiotics to children even for viral infections too. Adult are using antibiotics without prescription. Refilling and sharing of prescription is also common in our city. Here is myth that one antibiotic that proves beneficial to one patient; they share it with others who are suffering from same condition.

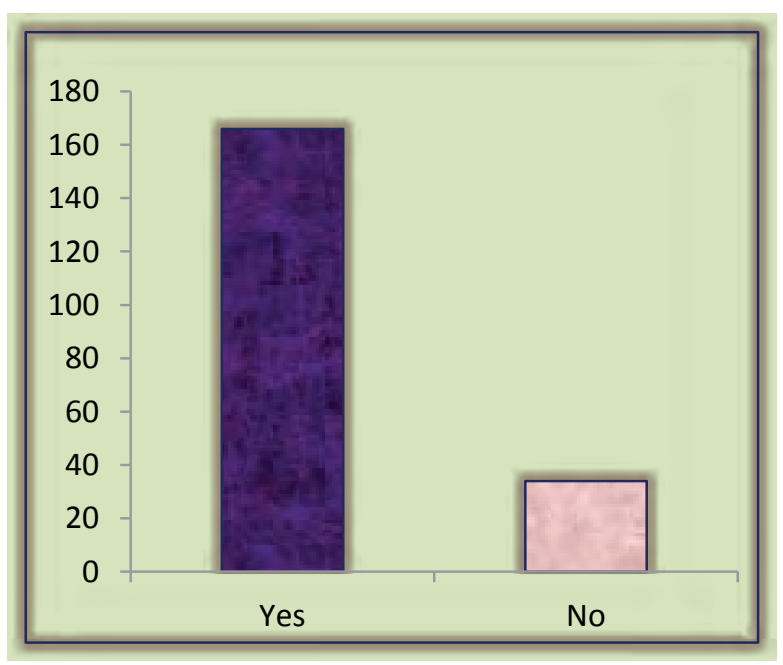

Figure 6: Follow complete course of antibiotics.

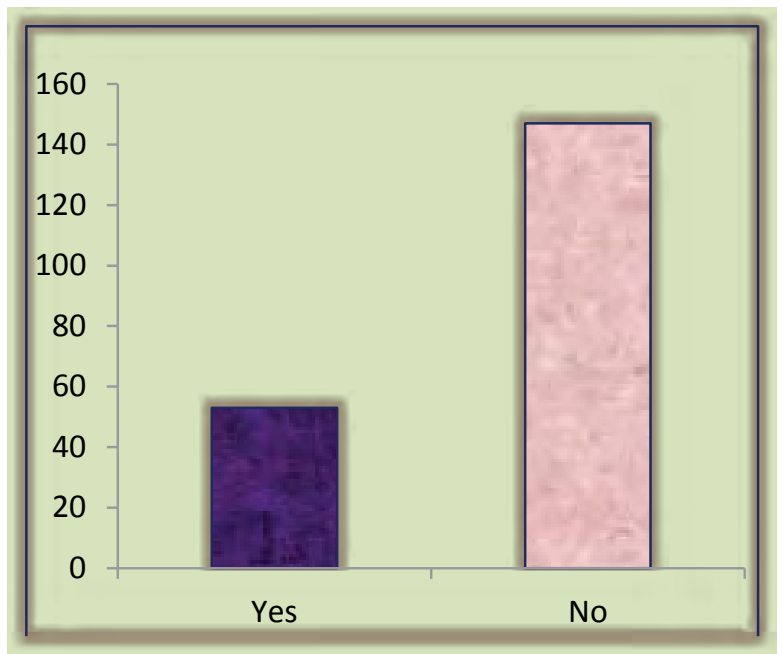

Figure 7: Experienced any of minor or serious adverse effects to antibiotics. 
Citation: Hameed A, Naveed S, Qamar F, Alam T, Abbas SS, et al. (2016) Irrational Use of Antibiotics, in Different Age Groups of Karachi: A Wakeup Call for Antibiotic Resistance and Future Infections. J Bioequiv Availab 8: 242-245. doi: 10.4172/jbb.1000302

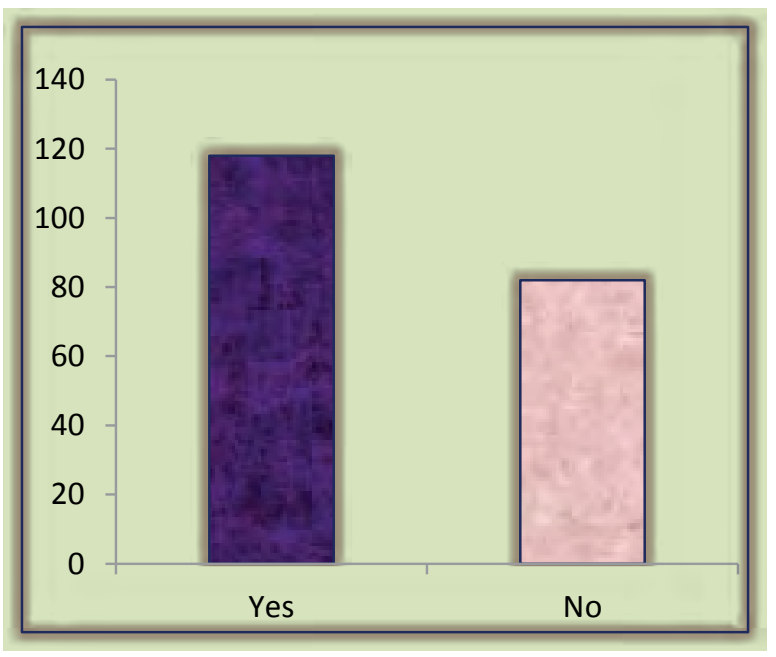

Figure 8: Knowledge about harm from misuse of antibiotics.

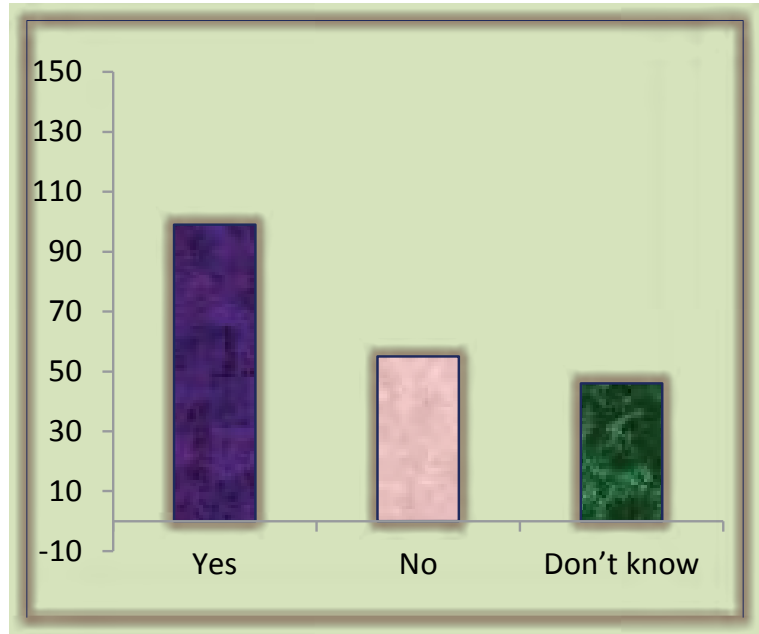

Figure 9: Awareness about effectiveness of antibiotics in treatment of same infection in future.

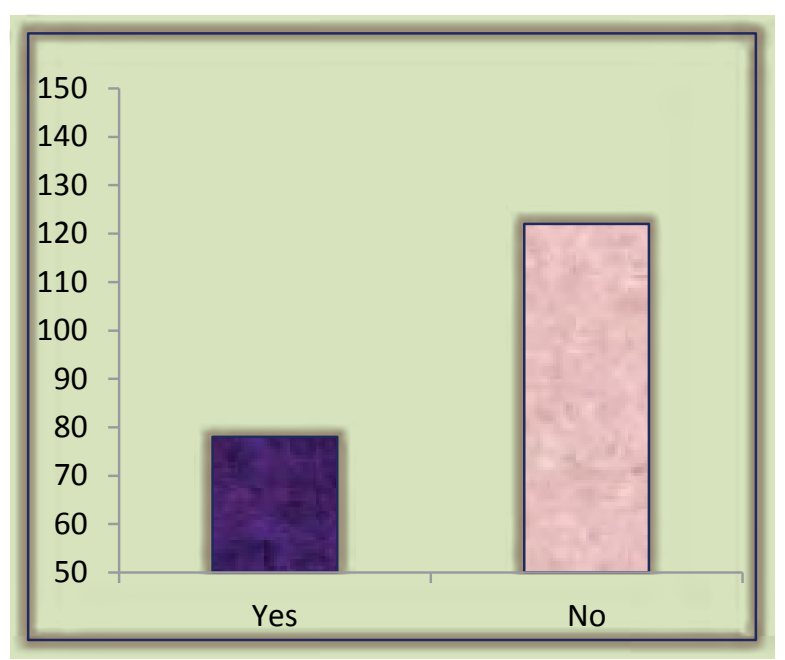

Figure 10: Refilling of previous prescription with antibiotics for same infections.

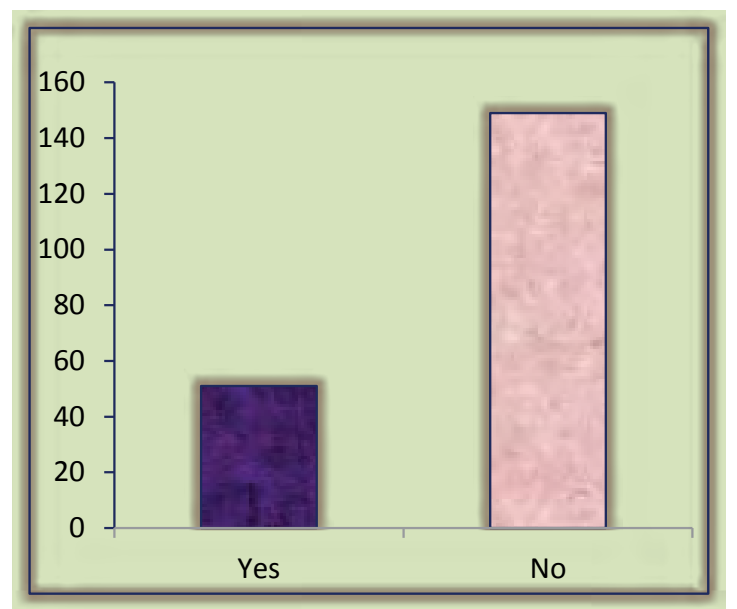

Figure 11: Sharing of prescription having antibiotics with others for same infections.

\section{References}

1. McDermott W, Rogers DE (1982) Social ramifications of control of microbial disease. The Johns Hopkins Medical Journal 151: 302-312.

2. Naveed S, Hameed A, Sharif N, Urooj A, Mehak R (2014) Use of 3rd generation cephalosporins in different age groups in tertiary health care centers of Karachi. Journal of Scientific and Innovative Research 3: 1-4.

3. Dubey AK, Subish P, Shankar PR, Upadhyay DK, Mishra P (2006) Prescribing patterns among pediatric inpatients in a teaching hospital in western Nepal. Singapore Med J 47: 261-265.

4. Ghai OP, Paul VK, Bagga A (2009) Disorders of respiratory system. Essential Pediatrics ( $7^{\text {th }}$ edn.) pp: 351-352.

5. Bharathiraja R, Sridharan S, Chelliah LR, Suresh S, Senguttuvan M (2005) Factors affecting antibiotic prescribing patterns in pediatric practice. Indian $J$ Paediatric 72: 877-880.

6. Moreland TA, Rylance GW, Cristopher LJ, Stevenson IH (1978) Patterns of drug prescribing for children in hospital. Eur J Clin Pharmacol 14: 39-46.

7. Naveed S, Qamar F, Maqsood A, Ayub A, Kauser H, et al. (2015) Prevalence and Consequences of Misuse of Antibiotics, Survey Based Study in Karachi. J Bioequiv Availab 7: 202-204.

8. Victor KE Lim (2012) The lack of novel antibiotic and vaccine development to combat resistance, APUA Clinical Newsletter.

9. http://www.nobelprize.org/nobel_prizes/medicine/laureates/1945/fleming lecture.html

10. Naveed S, Hameed A (2016) Analysis of Parts of Prescription in Common Practice. Int J Pharm P Pharm Sci 2: 1-4. 